\title{
New cytotoxic trichothecene macrolide epimers from endophytic Myrothecium roridum IFB-E012
}

\author{
Li Shen ${ }^{1,2}$, Li Zhu ${ }^{1}$, Qingwei Tan ${ }^{1}$, Dan Wan ${ }^{1}, \mathrm{Ju} \mathrm{Xie}^{3}$ and Jiangnan Peng ${ }^{4}$ \\ The Journal of Antibiotics (2016) 69, 652-655; doi:10.1038/ja.2016.86; published online 13 July 2016
}

Since the mixture of verrucarin A and B was obtained as the antibiotic glutinosin, from Myrothecium verrucaria in 1946, and pure verrucarin A and B, and roridin A were isolated from Myrothecium sp. in 1962, over 100 macrocyclic trichothecenes have been isolated from the culture of various microorganisms such as Myrothecium sp., Stachybotrys sp., Cylindrocarpon sp., Verticimonosporium sp., and Phomopsis $\mathrm{sp}^{1-6}$ These fungal macrocyclic trichothecenes have complex structures and most of them have a 12,13-epoxide group in the sesquiterpenoid moiety. ${ }^{2-4,6,7}$ Macrocyclic trichothecenes were classified as verrucarin, roridin, satratoxin, vertisporin and calcarisporin according to the variation of the macrolide ring. Macrocyclic trichothecenes exhibit significant bioactivity, especially anticancer activity, and this initiated further researches on their anticancer mechanism of action ${ }^{6,8,9}$ and structure-activity relationships. ${ }^{3,10}$

In our continuous characterization of macrocyclic trichothecenes from the endophyte, $M$. roridum IFB-E012, present in the traditional Chinese medicinal plant, Artemisia annua (Asteraceae), a new cytotoxic trichothecene macrolide dihydromyrothecine C (1), was isolated as an epimeric mixture due to an unstable cyclic hemiacetal structure. In this paper, we report the structures and bioactivity of the new trichothecene macrolide epimers.

Dihydromyrothecine C (1) was isolated as white needles and its molecular formula was deduced as $\mathrm{C}_{29} \mathrm{H}_{38} \mathrm{O}_{11}$ from the quasimolecular ion at $m / z 585.2311$ (calcd for $\mathrm{C}_{29} \mathrm{H}_{38} \mathrm{O}_{11} \mathrm{Na} 585.2306$ ) in the positive ESI-HR-MS, indicating 11 degrees of unsaturation. The ${ }^{1} \mathrm{H}$ - and ${ }^{13} \mathrm{C}-\mathrm{NMR}$ spectra of 1 revealed that it was a 10,13 cyclotrichothecane-derived macrolide similar to myrothecines $\mathrm{A}-\mathrm{C},{ }^{4}$ but it had two more hydrogens than myrothecine C. Moreover, the one-dimensional NMR spectra showed that there were duplicated resonances of protons and carbons assigned to the macrocyclic residue (from $\mathrm{C}-1^{\prime}$ to $\mathrm{C}-14^{\prime}$ ) in a ratio of $\sim 4: 5$. Attempting to separate this mixture was successful at low temperature (Supplementary Figure S9). However, when checked by HPLC immediately after separation without evaporation of the solvent, each separated peak showed exactly the same two peaks as before the separation. This clearly indicated that $\mathbf{1}$ existed in solution as a quickly equilibrating mixture of two stereoisomers (Figure 1). A close comparison of ${ }^{1} \mathrm{H}$ - and ${ }^{13} \mathrm{C}-\mathrm{NMR}$ spectra with those of myrothecine $\mathrm{C}$ demonstrated that 1 was identical to myrothecine $\mathrm{C}^{4}$ except for signals for an extra proton (1a: $\delta_{\mathrm{H}-14^{\prime}}=5.65$ p.p.m. and 1b: $\delta_{\mathrm{H}-14^{\prime}}=5.03$ p.p.m.) and a fully substituted carbon (1a: $\delta_{\mathrm{C}-14^{\prime}}=100.0$ p.p.m. and $\mathbf{1 b}$ : $\delta_{\mathrm{C}-14^{\prime}}=106.8$ p.p.m.) in place of the C-14' ester carbonyl at $\delta 175.6$ p.p.m. for myrothecine C, suggesting that 1 was a $14^{\prime}$-carbonyl reduction derivative of myrothecine $\mathrm{C}$. This was confirmed by a set of 2D NMR spectra (HMQC, HMBC and ${ }^{1} \mathrm{H}-{ }^{1} \mathrm{H}$ COSY). The HMBC

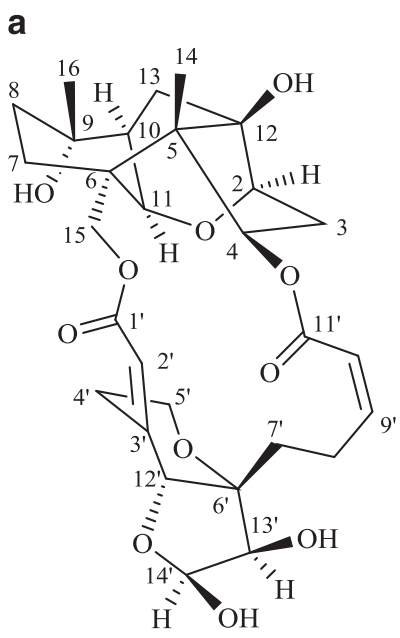

(major, 14'S-isomer)

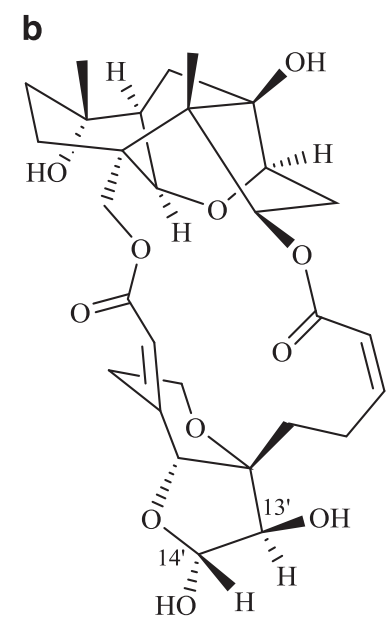

(minor, 14' $R$-isomer)
Figure 1 Structure of dihydromyrothecine C (1).

${ }^{1}$ Jiangsu Key Laboratory of Integrated Traditional Chinese and Western Medicine for Prevention and Treatment of Senile Diseases, Department of Pharmacy, Medical College of Yangzhou University, Yangzhou, China; ${ }^{2}$ Jiangsu Co-innovation Center for Prevention and Control of Important Animal Infectious Diseases and Zoonoses, Yangzhou, China; ${ }^{3}$ College of Chemistry and Chemical Engineering, Yangzhou University, Yangzhou, China and ${ }^{4}$ Department of Chemistry and Biochemistry, University of North Carolina at Wilmington, Wilmington, NC, USA

Correspondence: Dr L Shen, Jiangsu Key Laboratory of Integrated Traditional Chinese and Western Medicine for Prevention and Treatment of Senile Diseases, Medical College of Yangzhou University, Yangzhou 225001, China.

E-mail: shenli@yzu.edu.cn

or Dr J Peng, Department of Chemistry and Biochemistry University of North Carolina Wilmington, 601 S College Road, Wilmington, NC 28403, USA.

E-mail: pengj@uncw.edu

Received 27 February 2016; revised 13 June 2016; accepted 15 June 2016; published online 13 July 2016 
spectrum of 1 showed correlations of $\delta_{\mathrm{H}-14^{\prime}}$ (5.65 for $1 \mathrm{a}$ and 5.03 for $1 \mathbf{b})$ with $\delta_{\mathrm{C}-12^{\prime}}(84.0$ for $1 \mathbf{a}$ and 85.9 for $1 \mathbf{b})$ and $\delta_{\mathrm{C}-13^{\prime}}(73.9$ for 1a and 79.1 for $\mathbf{1 b}$ ), suggesting the formation of a hemiacetal between $\mathrm{C}-12^{\prime}$ and $\mathrm{C}-14^{\prime}$. The mixture was determined as the result of the epimerization of this hemiacetal group by coupling constants, COSY and NOESY spectra. The $\alpha$-orientation of $14^{\prime}-\mathrm{OH}$ in $\mathbf{1 b}$ was evident by NOE correlations between $\delta_{\mathrm{H}-14^{\prime}} 5.03(\mathbf{1 b})$ and $\delta_{\mathrm{H}-12^{\prime}} 3.95(\mathbf{1 b})$. In addition, the $\alpha$-orientation of $\mathrm{H}-13^{\prime}$ was suggested, as both $\mathrm{H}-13^{\prime}$ (1) and $\mathrm{H}-14^{\prime}(\mathbf{1 b})$ are singlets and only a weak NOE correlation between them was observed. The strong COSY and NOE correlations between $\delta_{\mathrm{H}-14^{\prime}} 5.65(1 \mathbf{a})$ and $\delta_{\mathrm{H}-13^{\prime}} 3.66(1 \mathbf{a})$, along with ${ }^{3} J_{\mathrm{H}-13^{\prime}, 14^{\prime}}=3.8 \mathrm{~Hz}$, a

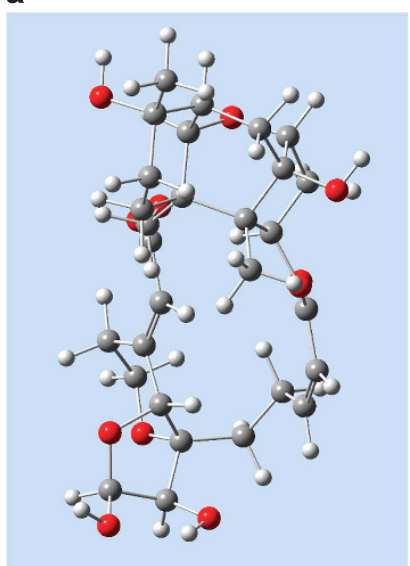

(major, 14'S-isomer)

Figure 2 Optimized conformations b3pw91/6-311g(d,p) level. b

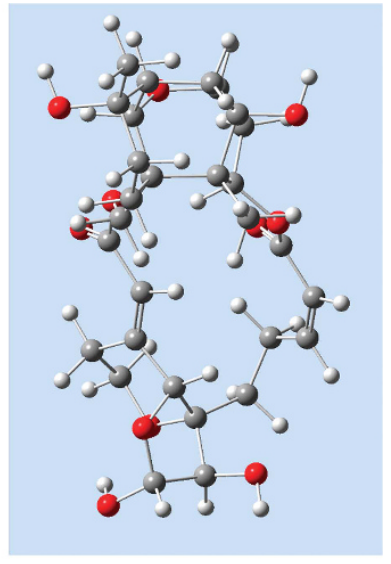

(minor, 14' $R$-isomer) confirmed that the $\mathrm{H}-13^{\prime}$ is $\alpha$-oriented. To confirm this result, a molecular modeling was conducted using Gaussian 09 at b3pw91/6-311g(d,p) level. The optimized conformations were shown in Figure 2. The calculated distances between $\mathrm{H}-14^{\prime} / \mathrm{H}-12^{\prime}$ ( $3.5 \AA$ in 1b), $\mathrm{H}-14^{\prime} / \mathrm{H}-13^{\prime}$ ( $2.4 \AA$ in $\mathbf{1 a}$ and $2.7 \AA$ in $\mathbf{1 b}$ ), and dihedral angles of $\mathrm{H}_{14^{\prime}}-\mathrm{C}_{14^{\prime}}-\mathrm{C}_{13^{\prime}}-\mathrm{H}_{13^{\prime}}\left(-24.9^{\circ}\right.$ in $\mathbf{1 a}$ and $91.0^{\circ}$ in $\left.\mathbf{1 b}\right)$ are consistent with the proposed configuration. Thus, the structure of dihydromyrothecine $\mathrm{C}$ was determined as a mixture of the $\mathrm{C}-14^{\prime}$ stereoisomers, as depicted in Figure 1. The absolute configuration of myrothecines A and $\mathrm{C}$ was previously determined by X-ray diffraction and Mosher's method. ${ }^{4}$ Dihydromyrothecine $\mathrm{C}$ is postulated to follow the same absolute configuration of myrothecines $\mathrm{A}$ and $\mathrm{C}$ because they are isolated from the culture of the same fungal strain. As methanol was used in the extraction and separation procedure, the stability of $\mathbf{1}$ in methanol was test by measuring ${ }^{1} \mathrm{H}$ NMR at $5 \mathrm{~min}, 4 \mathrm{~h}$ and $18 \mathrm{~h}$. No change was observed indicating that 1 was stable in methanol.

Biosynthetically, it could be hypothesized that hydroxylation of myrothecine A yielded myrothecine $\mathrm{B}$, and tautomerization of myrothecine B followed by acetal formation provided dihydromyrothecine $\mathrm{C}(\mathbf{1})$ as an equilibrium mixture (Scheme 1). The minimized energies of the conformations of the two epimers of dihydromyrothecine $\mathrm{C}, 14^{\prime} \mathrm{S}$ - and $14^{\prime} \mathrm{R}$-isomer, were calculated at b3pw91/6-311g $(\mathrm{d}, \mathrm{p})$ level and the conformers are shown in Figure 2. The optimized energies of $14^{\prime} S$-isomer and $14^{\prime} R$-isomer were -1955.12187 and -1955.12125 a.u. $\quad\left(1\right.$ a.u. $\left.=2625.505 \mathrm{~kJ} \mathrm{~mol}^{-1}\right)$, respectively. The calculation result indicated that $14^{\prime} S$-isomer was more stable than $14^{\prime} R$-isomer, which was in accordance with the phenomenon that $14^{\prime}$ $S$-isomer was the major conformer in solution as determined by the ${ }^{1} \mathrm{H}$ NMR spectrum of $\mathbf{1}$. The equilibrium mixture in solution caused by epimerization of cyclic hemiacetals has been reported. ${ }^{11-13}$

The in vitro cytotoxicity of $\mathbf{1}$ against the human nasopharyngeal carcinoma cell line KB was evaluated by the 3-(4,5-dimethylthiazol-2-

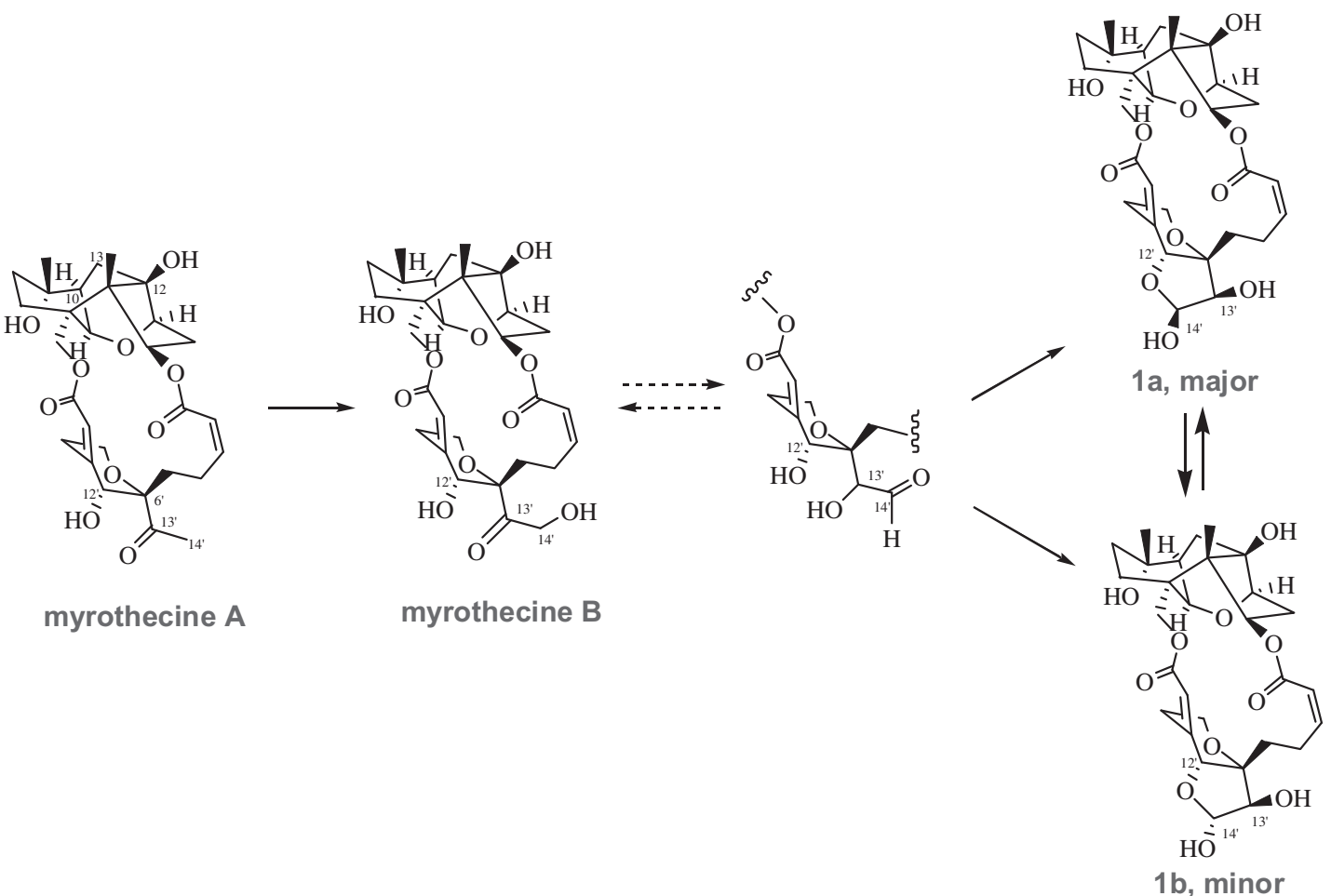

Scheme 1 Proposed biosynthesis of dihydromyrothecine C (1). A full color version of this scheme is available at The Journal of Antibiotics journal online. 
Table $1{ }^{1} \mathrm{H}-\mathrm{NMR}$ data for 1 and myrothecine $\mathrm{C}$ in acetone- $d_{6}$ recorded at $500 \mathrm{MHz}$ ( $\delta$ in p.p.m. and $J$ in $\mathrm{Hz}$ )

\begin{tabular}{|c|c|c|c|}
\hline Position & $\begin{array}{c}\text { 1a (major, } \\
\text { 14'S-isomer) }\end{array}$ & $\begin{array}{c}1 b \text { (minor, } \\
14^{\prime} \mathrm{R} \text {-isomer) }\end{array}$ & Myrothecine $C$ \\
\hline 2 & $3.88(d, 3.9)$ & $3.88(d, 3.9)$ & $3.89(\mathrm{~d}, 3.8)$ \\
\hline $3 \alpha$ & $2.12(\mathrm{~m})$ & $2.12(\mathrm{~m})$ & $2.15(\mathrm{~m})$ \\
\hline $3 \beta$ & $1.83(\mathrm{~m})$ & $1.83(\mathrm{~m})$ & $1.86(\mathrm{~m})$ \\
\hline 4 & $5.12(\mathrm{dd}, 8.2,3.1)$ & $5.13(\mathrm{dd}, 8.2,3.1)$ & $5.23(\mathrm{dd}, 8.0,2.9)$ \\
\hline $7 \alpha$ & $1.58(\mathrm{~m})$ & $1.58(\mathrm{~m})$ & $1.58(\mathrm{~m})$ \\
\hline $7 \beta$ & $2.15(\mathrm{~m})$ & $2.15(\mathrm{~m})$ & $2.11(\mathrm{~m})$ \\
\hline $8 \alpha$ & $1.35(\mathrm{br} \mathrm{dd}, 14.3,5.2)$ & 1.35 (br dd, $14.3,5.2)$ & $1.36(\mathrm{dd}, 14.3,5.2)$ \\
\hline $8 \beta$ & $1.76(\mathrm{~m})$ & $1.76(\mathrm{~m})$ & $1.82(\mathrm{~m})$ \\
\hline 10 & $2.08(\mathrm{~m})$ & $2.08(\mathrm{~m})$ & $2.16(\mathrm{~m})$ \\
\hline 11 & $3.56(d, 3.3)$ & $3.56(d, 3.3)$ & $3.59(d, 3.6)$ \\
\hline $13 \alpha$ & $1.85(\mathrm{~m})$ & $1.85(\mathrm{~m})$ & $1.91(\mathrm{~m})$ \\
\hline $13 \beta$ & $1.55(\mathrm{dd}, 13.8,5.4)$ & $1.55(\mathrm{dd}, 13.8,5.4)$ & $1.56(\mathrm{~m})$ \\
\hline 14 & $1.14(\mathrm{~s})$ & $1.14(\mathrm{~s})$ & $1.16(\mathrm{~s})$ \\
\hline $15 a$ & $4.45(d, 11.6)$ & $4.46(d, 11.6)$ & $4.50(d, 11.5)$ \\
\hline $15 b$ & $3.58(d, 11.6)$ & $3.60(d, 11.6)$ & $3.64(d, 11.5)$ \\
\hline 16 & $1.17(\mathrm{~s})$ & $1.17(\mathrm{~s})$ & $1.19(\mathrm{~s})$ \\
\hline $2^{\prime}$ & $5.94(\mathrm{~s})$ & $5.99(\mathrm{~s})$ & $6.26(\mathrm{~s})$ \\
\hline $4^{\prime} \alpha$ & $2.53(\mathrm{~m})$ & $2.70(\mathrm{~m})$ & $2.48(\mathrm{td}, 12.8,5.9)$ \\
\hline $4^{\prime} \beta$ & $3.40(\mathrm{br} \mathrm{d}, 12.5)$ & $3.45(\mathrm{br} \mathrm{d}, 12.5)$ & 3.55 (br d, 13.0) \\
\hline $5^{\prime} \alpha$ & $3.83(\mathrm{~m})$ & $3.95(\mathrm{~m})$ & $3.88(\mathrm{~m})$ \\
\hline $5^{\prime} \beta$ & $4.09(\mathrm{~m})$ & $4.14(\mathrm{~m})$ & $4.26(\mathrm{td}, 12.8,2.2)$ \\
\hline 7'a & $1.75(\mathrm{~m})$ & $1.75(\mathrm{~m})$ & $1.88(\mathrm{~m})$ \\
\hline 7 'b & $1.70(\mathrm{~m})$ & $1.70(\mathrm{~m})$ & $1.82(\mathrm{~m})$ \\
\hline $8{ }^{\prime} a$ & $2.83(\mathrm{~m})$ & $2.83(\mathrm{~m})$ & $2.89(\mathrm{~m})$ \\
\hline $8^{\prime} b$ & $1.92(\mathrm{~m})$ & $1.92(\mathrm{~m})$ & $1.95(\mathrm{~m})$ \\
\hline $9^{\prime}$ & $6.51(\mathrm{~m})$ & $6.51(\mathrm{~m})$ & $6.55(\mathrm{~m})$ \\
\hline $10^{\prime}$ & $5.82(d, 11.5)$ & $5.82(d, 11.6)$ & $5.86(\mathrm{dd}, 11.5,2.1)$ \\
\hline $12^{\prime}$ & $4.01(\mathrm{~s})$ & $3.95(\mathrm{~s})$ & $4.61(\mathrm{~s})$ \\
\hline $13^{\prime}$ & $3.66(d, 3.8)$ & $3.73(\mathrm{~s})$ & 3.79 (s) \\
\hline $14^{\prime}$ & $5.65(d, 3.6)$ & $5.03(\mathrm{~s})$ & \\
\hline
\end{tabular}

yl)-2,5-diphenyl tetrazolium bromide (MTT) method. Compound 1 showed moderate cytotoxicity against $\mathrm{KB}$ cells with an half maximal inhibitory concentration $\left(\mathrm{IC}_{50}\right)$ value of $44.48 \mu \mathrm{M}$, whereas the control, 5-fluorouracil (5-FU) had an $\mathrm{IC}_{50}$ value of $14 \mu \mathrm{M}$.

Many researchers have shown that minor structural variation of macrocyclic trichothecenes significantly affected their anticancer activity. 10,13-Cyclotrichothecane macrolides mainly found in symbiotic fungi were proved to be less cytotoxic., ${ }^{3,4}$ Change of the $2^{\prime}, 3^{\prime}$ double bond to $2^{\prime}-\mathrm{OH}$ could effectively increase the cytotoxicity, whereas breakage of the macrocyclic ring greatly reduces the activity. ${ }^{3}$ Macrocyclic trichothecenes bearing the tetrahydropyranyl ring within the macrolide chain are considerably more potent than other roridins and verrucarins. ${ }^{14}$ Reduction of the $7^{\prime}, 8^{\prime}, 9^{\prime}, 10^{\prime}$-diene system diminished cytotoxicity greatly, especially reduction of the $7^{\prime}, 8^{\prime}$-double bond. ${ }^{14}$ The stereochemistry at $\mathrm{C}^{\prime}-\mathrm{C} 13^{\prime}$ also has a role in affecting both selectivity and potency. ${ }^{3}$ Therefore, seeking new macrocyclic trichothecenes from fungal metabolites for extensive structure-activity relationship investigation can help to develop new trichothecene macrolide-type anticancer drugs in the future.

\section{EXPERIMENTAL PROCEDURE}

\section{General}

Melting point was measured on an XT-4 apparatus and was uncorrected. The IR spectrum was determined in a $\mathrm{KBr}$ disk on a
Table $2{ }^{13}$ C-NMR data for 1 and myrothecine $C$ in acetone- $d_{6}$ recorded at $500 \mathrm{MHz}$ ( $\delta$ in p.p.m. and $J$ in $\mathrm{Hz}$ )

\begin{tabular}{|c|c|c|c|}
\hline Position & 1a (major, 14'S-isomer) & $1 b$ (minor, 14'R-isomer) & Myrothecine $\mathrm{C}$ \\
\hline 2 & 81.3 & 81.3 & 84.4 \\
\hline 3 & 41.0 & 41.0 & 40.9 \\
\hline 4 & 79.1 & 79.1 & 79.1 \\
\hline 5 & 51.5 & 51.5 & 51.6 \\
\hline 6 & 44.2 & 44.2 & 44.3 \\
\hline 7 & 28.6 & 28.6 & 27.6 \\
\hline 8 & 31.4 & 31.4 & 31.6 \\
\hline 9 & 72.7 & 72.7 & 72.6 \\
\hline 10 & 44.6 & 44.6 & 44.8 \\
\hline 11 & 69.8 & 69.8 & 69.8 \\
\hline 12 & 77.1 & 77.1 & 77.2 \\
\hline 13 & 29.0 & 29.0 & 30.4 \\
\hline 14 & 10.6 & 10.6 & 10.6 \\
\hline 15 & 73.7 & 73.7 & 73.9 \\
\hline 16 & 27.5 & 27.5 & 25.8 \\
\hline $1^{\prime}$ & 166.2 & 166.2 & 165.7 \\
\hline $2^{\prime}$ & 117.1 & 117.5 & 120.2 \\
\hline $3^{\prime}$ & 154.6 & 154.3 & 149.5 \\
\hline $4^{\prime}$ & 26.4 & 26.4 & 24.4 \\
\hline $5^{\prime}$ & 65.0 & 65.4 & 65.0 \\
\hline $6^{\prime}$ & 88.3 & 87.5 & 83.8 \\
\hline $7^{\prime}$ & 25.1 & 24.6 & 28.7 \\
\hline $8^{\prime}$ & 21.6 & 21.7 & 21.5 \\
\hline $9^{\prime}$ & 148.0 & 148.0 & 147.9 \\
\hline $10^{\prime}$ & 121.8 & 121.8 & 122.1 \\
\hline $11^{\prime}$ & 166.9 & 166.9 & 166.8 \\
\hline $12^{\prime}$ & 84.0 & 85.9 & 81.3 \\
\hline $13^{\prime}$ & 73.9 & 79.1 & 73.0 \\
\hline $14^{\prime}$ & 100.0 & 106.8 & 175.6 \\
\hline
\end{tabular}

Nexus 870 FT-IR spectrometer (Thermo Nicolet Corporation, Madison, WI, USA). NMR spectra were acquired on a Bruker DRX-500 spectrometer (Bruker Corporation, Karlsruhe, Germany) using solvent signals as internal standards. ESI-HR-MS was taken on a Mariner Mass 5304 instrument (Applied Biosystems, Lincoln, CA, USA). Silica gel (200-300 mesh) for column chromatography and silica $\mathrm{GF}_{254}$ for TLC were produced by Qingdao Marine Chemical Company, Qingdao, China. Octadecylsilyl silica gel was from Nacalai Tesque, Kyoto, Japan. HPLC analysis was performed on an Agilent 1260 (Agilent Technologies Inc., Santa Clara, CA, USA) using a Sinochrom ODS-AP column $(5 \mu \mathrm{m}, 250 \times 4.6 \mathrm{~mm})$ from Dalian Elite Analytical Instruments Co., Ltd (Dalina, China). The enzyme-linked immunosorbent assay plate reader was from Sunrise, Tecan Company, Switzerland. Fetal bovine serum was produced by Hangzhou Sijiqing Co (Hangzhou, China). RPMI-1640 and MTT were purchased from Gibco Co. (New York, NY, USA). 5-FU was provided by the Medical College of Nantong University, China. The human nasopharyngeal carcinoma cell line KB was supplied by Nanjing University, China.

\section{Microorganism}

Strain IFB-E012 was isolated from surface-sterilized stems of apparently healthy A. аnnua collected in May 2003 from the coast of the Yangtze River (Nanjing, China). It was identified as M. roridum by comparing the morphological character and $18 \mathrm{~S}$ ribosomal DNA sequence with those of standard records; ${ }^{4}$ the sequences of the strain have been deposited in GenBank (DQ102373). M. roridum IFB-E012 
is kept at the Institute of Functional Biomolecules, Nanjing University, China.

\section{Extraction and isolation}

M. roridum IFB-E012 was cultured in liquid medium and the culture filtrate was extracted exhaustively with ethyl acetate. ${ }^{4}$ Evaporation of the solvent from the extract in vacuo yielded a black residue $(35 \mathrm{~g})$. The extract was dissolved in methanol and $\mathrm{H}_{2} \mathrm{O}$ in a ratio of 85 to 15 (v/v) and then kept at $-4{ }^{\circ} \mathrm{C}$ overnight. After removing of the waxy substances by filtration and evaporation of the filtrate, a residue (27 $\mathrm{g}$ ) was obtained. This residue was then chromatographed over a silica gel column eluted successively with $\mathrm{CHCl}_{3} / \mathrm{MeOH}$ gradient $(100: 0 \rightarrow 0: 100, v / v)$ to provide six fractions (Fr.-1 $\sim$ Fr.-6). Fr.-4 $(3.0 \mathrm{~g})$ was subjected to further column chromatography fractionation over silica gel with $\mathrm{CHCl}_{3} / \mathrm{MeOH}$ gradient $(100: 0 \rightarrow 100: 32, \mathrm{v} / \mathrm{v})$. Then, purification of Fr-4-2 (0.9 g) on ODS silica gel column chromatography eluting with $\mathrm{H}_{2} \mathrm{O} / \mathrm{MeOH}(100: 0 \rightarrow 60: 40)$ gave $10 \mathrm{mg}$ of $\mathbf{1}$.

1 (dihydromyrothecine C): white needle crystals (acetone); melting point $208-210^{\circ} \mathrm{C}$; IR $(\mathrm{KBr}) \nu_{\max } 3494,3330,2963,1713,1686,1253$, $1226,1188,1155,1097,1058,1020$ and $1008 \mathrm{~cm}^{-1} ;{ }^{1} \mathrm{H}-$ and ${ }^{13} \mathrm{C}-$ NMR data were given in Tables 1 and 2; (+)-ESI-HR-MS $\mathrm{m} / \mathrm{z}$ 585.2311 $[\mathrm{M}+\mathrm{Na}]^{+}$(calcd for $\mathrm{C}_{29} \mathrm{H}_{38} \mathrm{O}_{11}$ 585.2306).

\section{Theoretical calculations}

All calculations were performed using the Gaussian 09 suite of programs. ${ }^{15}$ For two isomers of dihydromyrothecine C, full geometry optimizations, vibrational frequency calculation as well as energy calculation were performed at the b3pw91/6-311 $\mathrm{g}(\mathrm{d}, \mathrm{p})$ level of theory. ${ }^{16,17}$

\section{Cytotoxicity assay}

In vitro cytotoxicity of $\mathbf{1}$ was evaluated using the MTT method as described previously. ${ }^{18}$

\section{CONFLICT OF INTEREST}

The authors declare no conflict of interest.

\section{ACKNOWLEDGEMENTS}

This work was financially supported by the National Natural Science Foundation of China (nos 21372191 and 30701045). This article is dedicated to the fond memory of the late Professor Lester Mitscher, a great scholar, teacher and Emeritus Editor of this Journal.

1 Grove, J. F. Macrocyclic trichothecenes. Nat. Prod. Rep. 10, 429-448 (1993)

2 Yu, N. J., Guo, S. X. \& Xiao, P. G. New sesquiterpene esters from the culture filtrate of Calcarisporium arbuscula isolated from Ganoderma lucidum. Acta Bot. Sin. 44, 878-882 (2002).

3 Amagata, T. et al. Structures and cytotoxic properties of trichoverroids and their macrolide analogues produced by saltwater culture of Myrothecium verrucaria. J. Med. Chem. 46, 4342-4350 (2003).

4 Shen, L. et al. Absolute configuration of new cytotoxic and other bioactive trichothecene macrolides. Chem. Eur. J. 12, 5596-5602 (2006).

$5 \mathrm{Xu}, \mathrm{J}$. Z. et al. Four new macrocyclic trichothecenes from two strains of marine-derived fungi of the genus Myrothecium. J. Antibiot. 59, 451-455 (2006).

6 Lin, T. et al. Structure elucidation and biological activity of two new trichothecenes from an endophyte, Myrothecium roridum. J. Agric. Food Chem. 62, 5993-6000 (2014).

7 Breitenstein, W. \& Tamm, C. Verrucarin K, the first natural trichothecene derivative lacking the 12,13-Epoxy group. Helv. Chim. Acta 60, 1522-1527 (1977).

8 Oda, T. et al. Verrucarin A inhibition of MAP kinase activation in a PMA-stimulated promyelocytic leukemia cell line. Mar. Drugs 3, 64-73 (2005).

$9 \mathrm{Xu}, \mathrm{H}$. J. et al. Molecular mechanism of mytoxin B and myrothecine A in inhibiting proliferation of SMMC-7721 of hepatocarcinoma cells. J. Clin. Med. Pract. 18, 1-5 (2014).

10 Steinmetz, W. E., Rodarte, C. B. \& Lin, A. 3D QSAR study of the toxicity of trichothecene mycotoxins. Eur. J. Med. Chem. 44, 4485-4489 (2009).

$11 \mathrm{Ni}$, M., Zhou, X. Y., He, X. \& Gu, Q. Q. A novel hemiacetal from the marine-derived fungus Penicillium citrinum. Acta Pharm. Sin. 46, 1098-1100 (2011).

12 Zhao, S. S. Equilibrium between $\alpha$ - and $\beta$-isomers of dihydroartemisinine and its multiple-peaks in high-performance liquid chromatography. Chromatographia 22 , 77-80 (1986).

13 Kutrzeba, L. M., Ferreira, D. \& Zjawiony, J. K. Salvinorins J from Salvia divinorum: mutarotation in the neoclerodane system. J. Nat. Prod. 72, 1361-1363 (2009).

14 Jarvis, B. B. et al. Novel macrocyclic trichothecenes from Myrothecium roridum. Bull. Soc. Chim. Belg. 95, 681-697 (1986).

15 Frisch, M. J. et al. in Gaussian 09, Revision B.O1 (Gaussian, Inc., Wallingford CT, 2010).

16 Becke, A. D. Density-functional thermochemistry. III. The role of exact exchange. J. Chem. Phys. 98, 5648-5652 (1993).

17 Perdew, J. P. et al. Atoms, molecules, solids, and surfaces: applications of the generalized gradient approximation for exchange and correlation. Phys. Rev. B 46, 6671-6687 (1992).

18 Shen, L. et al. Structure and total synthesis of aspernigerin: a novel cytotoxic endophyte metabolite. Chem. Eur. J. 12, 4393-4396 (2006).

Supplementary Information accompanies the paper on The Journal of Antibiotics website (http://www.nature.com/ja) 